\title{
TEOLOGI AGAMA-AGAMA MENURUT PEMIKIRAN LESSLIE NEWBIGIN DAN JOHAN HERMAN BAVINCK
}

\author{
Doni Herwanto Harianja ${ }^{1}$, Antonius S. Un ${ }^{2}$ \\ 12 STT Reformed Injili Internasional
}

Korespondensi: donher.harianja@gmail.com; antoniussteven@gmail.com

ABSTRACT: This article examines both Lesslie Newbigin and Johan Herman Bavinck's theologies of religions. It is argued that people from Reformed theological tradition and those who are exclusivist have no interest in dialogue and tend to have negative views about the existence of religion. By taking these two figures, the author compares the concept of religion and attitude or approach toward the religions of Newbigin and Bavinck. From this study, the author shows the diversity of theology of religions from Reformed theological tradition.

KEYWORDS: Lesslie Newbigin; Johan Herman Bavinck; mission; theology of religions; general revelation; exclusivism; inclusivism; Christianity and other religions.

ABSTRAK: Artikel ini mengkaji teologi agama-agama menurut pandangan Lesslie Newbigin dan Johan Herman Bavinck. Dikatakan bahwa orangorang dari tradisi teologi Reformed, dan yang berpandangan eksklusivisme tidak tertarik untuk berdialog dan cenderung berpandangan negatif tentang keberadaan agama. Dengan mengambil kedua tokoh ini, maka penulis membandingkan antara konsep agama maupun sikap atau pendekatan Newbigin dengan konsep agama maupun sikap atau pendekatan Bavinck. Dari kajian ini, penulis memperlihatkan keragaman teologi agama-agama dari tradisi teologi Reformed.

KATA KUNCI: Lesslie Newbigin; Johan Herman Bavinck; misi; teologi agamaagama; wahyu umum; ekslusivisme; inklusivisme; Kristen dan agama lain. 


\section{Pendahuluan}

Dalam deklarasi Nostra Aetate dari Konsili Vatikan II terdapat pernyataan-pernyataan yang menandai titik balik dalam hubungan Gereja Katolik Roma dan agama-agama non-Kristen. ${ }^{1}$ Deklarasi tersebut secara khusus menyebutkan beberapa agama yang dipercayai di dunia, yakni agama Hindu, Buddha, Islam, dan Yudaisme. Pada butir ke-2 Nostra Aetate, yang menjelaskan mengenai agama Hindu, disebutkan

..men contemplate the divine mystery and express it through an inexhaustible abundance of myths and through searching philosophical inquiry. They seek freedom from the anguish of our human condition either through ascetical practices or profound meditation or a flight to God with love and trust. ${ }^{2}$

Sebagai respon dari pernyataan yang tercantum dalam deklarasi Nostra Aetate terkait agama Hindu, Gereja Katolik memposisikan dirinya untuk tidak menolak apapun yang benar dan suci dalam agama-agama tersebut. Justru gereja Katolik mengambil sikap untuk menghormati konsep dan praktik dalam kehidupan dari ajaran maupun dogma agama non-Kristen, meskipun banyak perbedaan dengan ajaran Katolik dalam berbagai aspek. Gereja Katolik percaya bahwa ajaran maupun dogma dalam agama lain mengandung benih 'Kebenaran Absolut'.

Klaim dari Gereja Katolik ini tentunya mempunyai dasar, yang diambil dari pandangan para Bapa Gereja yang menyatakan bahwa agama-agama merefleksikan satu kebenaran atau 'benih Sabda' (seeds of the Word). ${ }^{3}$ Maka dari itu, salah seorang Paus, yakni Paus Santo Yohanes Paulus II, mengungkapkan bahwa "the Holy Spirit sowing 'seeds of the Word' in the various cultures of the world, preparing them 'for full maturity in Christ'"' ${ }^{4}$ Perihal deklarasi yang tertuang dalam Nostra Aetate, Barnes menyatakan "this is classic Catholic fulfilment (or ... "inclusivist") theology; the grace that makes salvation possible is given in virtue of Christ". ${ }^{5}$ Lalu bagaimana dengan tradisi teologi Reformed dalam meresponi keragaman agama yang ada di dalam dunia?

\footnotetext{
1 Pope Paul VI, "Declaration on the Relation of the Church to non-Christian Religions-Nostra Aetate," Vatican.va, October 28, 1965. https://www.vatican.va/archive/hist_councils/ii_vatican_council/ documents/vat-ii_decl_19651028_nostra-aetate_en.html (Diakses 11 Januari 2022)

2 Pernyataan dalam butir ke-2 yang terdapat dalam Pope Paul VI, "Declaration on the Relation of the Church to non-Christian Religions-Nostra Aetate," Vatican.va, October 28, 1965.

3 Pernyataan ini dikutip dalam Kathleen Taylor, "Talking with Other Religions." The Way 59, no. 1 (January 2020): 47-57 dan juga dalam Jacques Dupuis, Towards a Christian Theology of Religious Pluralism (Maryknoll: Orbis, 1997), 174.

4 John Paul II, “Redemptoris Missio," Vatican.va, December 7, 1990. Butir ke-28. https://www.vatican.va/content/john-paul-ii/en/encyclicals/documents/hf_jp-ii_enc_07121990_redemptoris-missio.html (Diakses 11 Januari 2022).

5 Michael Barnes, Interreligious Learning: Dialogue, Spirituality and the Christian Imagination (Cambridge: CUP, 2012), 14.
} 
Umumnya, pembahasan tentang teologi agama-agama, tidak terlepas dari pendekatan tripolar yang dicetuskan oleh Alan Race pada tahun 1982. Dalam bukunya tersebut, yang berjudul Christians and Religious Pluralism ${ }^{6}$, Alan Race meringkas tiga pendekatan dasar Kristen dalam menanggapi keragaman agama, yaitu "ekslusivisme" (Kristen sendiri adalah agama yang benar), "inklusivisme" (kepenuhan dari semua tradisi kepercayaan dan agama ada di dalam Kristen), dan "pluralisme" (pandangan teosentris yang diajukan oleh John Hick). ${ }^{7}$

Terhadap tiga pendekatan dari Alan Race ini, Martha Moore-Keish berargumen bahwa orang dengan tradisi teologi Reformed akan cenderung kepada eksklusivisme. ${ }^{8}$ Merujuk pada pandangan Karl Barth, salah satu teolog tradisi Reformed yang berpandangan ekslusivisme, Moore-Keish menjelaskan

God can be known only through God's self revelation in Jesus Christ, not through any other means...[So] Barth argued that looking for points of contact between Christianity and other religious traditions is the wrong starting point. Human religion is "unbelief," and it starts with human effort, rather than turning to God's revelation. ${ }^{9}$

Moore-Keish berpendapat bahwa "Reformed folks have shunned all human efforts to reach God in favor of God's gracious approach to us in Jesus Christ". ${ }^{10}$ Meski orang Reformed berpikiran demikian, Moore-Keish juga menyatakan bahwa orang Reformed secara naif mengabaikan aspek-aspek dari keterlibatan agama yang tidak jarang ditemukan sangat kejam dalam kehidupan manusia, yakni terdapat perlakuan kejam di mana orang-orang Kristen menyiksa orang Yahudi, atau Hindu militan membantai Muslim, atau para penganut fundamentalis agama apapun yang beralih kepada kekerasan sebagai satu-satunya cara untuk mempertahankan hidup mereka. ${ }^{11}$ Selain itu, menurut Kathleen Taylor dengan merujuk pada Gavin D'Costa, orangorang yang berpandangan ekslusivisme menolak untuk berdialog, atau tidak tertarik pada apapun yang menyangkut orang tidak percaya. ${ }^{12}$

\footnotetext{
6 Pembahasan tripolar dari Alan Race dapat dilihat lebih lanjut dalam Alan Race, Christians and Religious Pluralism: Patterns in the Christian Theology of Religions (Maryknoll, N.Y.: Orbis Books, 1982).

7 Martha L. Moore-Keish, "Divine Freedom and Human Religions: A Reformed Theologian Approaches Comparative Theology," Theology Today 75, no. 3 (2018): 289. doi:10.1177/0040573618791732.

8 Martha L. Moore-Keish, "Presbyterians, Religious Diversity, and World Religions." Dalam The Oxford Handbook of Presbyterianism, Edited by Gary Scott Smith (New York: Oxford University Press, 2019), 449. Mengenai orang dari tradisi teologi Reformed yang umumnya berpandangan ekslusivisme, juga dinyatakan oleh Kathleen Taylor, "In Christianity [exclusivism] is often associated with conservative Protestant evangelicals or Calvinists" dalam "Talking with Other Religions." The Way 59, no. 1 (January 2020): 48.

9 Moore-Keish, "Presbyterians, Religious Diversity, and World Religions", 449-450.

10 Moore-Keish, "Divine Freedom and Human Religions", 291.

11 Ibid., 292.

12 Dapat dilihat dalam Gavin D'Costa, Christianity and World Religions: Disputed Questions in the
} 
Terhadap pemaparan di atas, penulis berargumen bahwa pernyataan yang ditujukan kepada orang-orang yang berpandangan eklusivisme, dan juga berasal dari tradisi teologi Reformed, tidak relevan. Untuk membuktikannya, penulis akan menjelaskannya dengan memaparkan pemikiran dua tokoh misionaris dari tradisi teologi Reformed, yakni Lesslie Newbigin dan Johan Herman Bavinck. ${ }^{13}$ Penulis mengambil kedua tokoh ini karena terdapat perbedaan di antara keduanya, yaitu Bavinck secara spesifik adalah seorang misionaris dari tradisi pemikiran neo-Calvinisme. ${ }^{14}$ Dengan mengambil kedua pemikiran tokoh ini, selain untuk membuktikan argumen penulis, penulis juga hendak menyajikan perbedaan di antara keduanya dalam menyikapi fenomena keragaman agama di ladang misi.

\section{Metode}

Penulis akan memaparkan pemahaman Newbigin dan Bavinck secara deskriptif yang berkenaan dengan teologi agama-agama. Kemudian, dengan memakai metode kerja komparatif, penulis akan membandingkan antara pemikiran teologi agama-agama Newbigin dengan pemikiran Bavinck. Selanjutnya penulis akan mendaftarkan dan menganalisis perbedaan di antara keduanya. Pada bagian akhir, penulis akan memberikan kesimpulan sehubungan dengan argumentasi yang diajukan.

\section{Teologi Agama-Agama dalam Pemikiran Lesslie Newbigin Agama Menurut Lesslie Newbigin}

Newbigin berpendapat bahwa kata "agama" dapat digunakan untuk menjelaskan sistem kepercayaan dan praktek apapun, yang menyiratkan hal-hal yang bersifat transenden dari pengalaman indera. Selain itu, kata "agama" juga dapat digunakan untuk mengacu kepada keyakinan dan praktek yang berhubungan dengan Tuhan dan jiwa yang kekal. ${ }^{15}$ Namun terhadap kata "agama”, Newbigin lebih mengacu kepada otoritas akhir tertinggi yang

\footnotetext{
Theology of Religions (Oxford: Wiley-Blackwell, 2009), 29 dan dalam Kathleen Taylor, "Talking with Other Religions." The Way 59, no. 1 (January 2020): 48.

13 Lesslie Newbigin secara eksplisit menyatakan bahwa dirinya berpandangan ekslusivisme: "the position which I have outlined is exclusivist in the sense that it affirms the unique truth of the revelation in Jesus Christ" dapat dilihat dalam Lesslie Newbigin, The Gospel in a Pluralist Society (Grand Rapids, MI: William B. Eerdmans, 1989), 192. Sedangkan Johan Herman Bavinck tidak secara eksplisit menyatakan dirinya berpandangan ekslusivisme. Tetapi, perihal ekslusivisme ini dapat dilihat dari definisi misi yang diberikan: "Missions is that activity of the church - in essence it is nothing else than an activity of Christ, exercised through the church - through which the church...calls the peoples of the earth to repentance and to faith in Christ". Lihat dalam J.H. Bavinck, An Introduction to the Science of Missions (Phillipsburg, N.J: P \& R Publishing, 1960), 62.

14 John Bolt, "Why a Bavinck Institute? Why at Calvin Seminary?" Calvin Theological Journal 52, no. 2 (November 2017): 251-63.

15 Lesslie Newbigin, The Open Secret: An Introduction to the Theology of Mission, rev. ed. (Grand Rapids, Mich.: W.B. Eerdmans, 1995), 160-161.
} 
diyakini oleh seseorang maupun masyarakat. Otoritas ini digunakan untuk menentukan skala nilai seseorang dan memberikan model ataupun pola, yang diperlukan oleh seseorang ataupun masyarakat untuk memahami dan mengatur pengalamannya. ${ }^{16}$ Maka dari itu, penjelasan Newbigin mengenai agama-agama akan berkaitan erat dengan komitmen penganutnya.

Sebagai seorang misionaris, Newbigin menaruh seluruh komitmen tanpa syaratnya kepada Yesus Kristus, sebab seluruh otoritas ada pada Pribadi Yesus Kristus. ${ }^{17}$ Melalui Yesus Kristus, Allah menyatakan keberadaan-Nya dan berkemah di antara umat manusia. Selain itu, Kristus adalah wujud nyata dari Firman, yang melalui-Nya segala sesuatu diciptakan. Selaras dengan pembukaan Injil Yohanes, Newbigin menyatakan bahwa Yesus Kristus adalah Allah. ${ }^{18}$ Oleh sebab itu, bila agama non-Kristen dianggap sebagai sarana Allah untuk menyatakan rencana penebusan dan keselamatan-Nya, maka Newbigin menolak hal ini.

Penolakan Newbigin berkaitan erat dengan keunikan Pribadi Yesus Kristus yang ada di dalam Perjanjian Lama. Dalam Perjanjian Lama, baik para nabi, Musa, Daud, dan Yohanes Pembaptis, memberikan kesaksian tentang Kristus, yang adalah pusat atau fokus dari kesaksian tersebut. Selain itu, Yesus Kristus adalah realita tertinggi yang telah datang ke dunia dan diam di tengah-tengah umat manusia. Bila agama non-Kristen juga dianggap sebagai salah satu sarana penyataan Allah, maka keunikan Pribadi Kristus yang sudah dinyatakan dalam Perjanjian Lama tidak diakui dan diabaikan. ${ }^{19}$

Newbigin secara tegas mengklaim bahwa keyakinan terhadap keunikan Pribadi Yesus Kristus, sangat mutlak diperlukan. ${ }^{20}$ Keunikan Pribadi Kristus dinyatakan oleh Newbigin sebagai berikut:

[the incarnation, life, death, and resurrection of Jesus] is an absolutely unique event in history by which the whole human situation is changed. It is not merely the communication of divine truth, but the restoration of mankind to the proper relationship with God. It is a revealing which necessarily involves a veiling, because man estranged from God does not recognize God. The revelation therefore involves contradiction. It can be received only in faith. The action of God in Jesus Christ has made possible what is otherwise impossible, "that sinful man can walk with God the holy and righteous in unbroken and undefiled fellowship". ${ }^{21}$

16 Newbigin, The Open Secret, 160.

17 Ibid.

18 Lesslie Newbigin, The Light Has Come: An Exposition of the Fourth Gospel (Grand Rapids, Mich.: W.B. Eerdmans, 1982), 8, 10.

19 Lesslie Newbigin, "Religious Pluralism and the Uniqueness of Jesus Christ." International Bulletin of Missionary Research 13, no. 2 (April 1989): 50.

20 Lesslie Newbigin, "Way out West: The Gospel in a Post-Enlightenment World." Touchstone (US) 5, no. 3 (Sum 1992): 23.

21 Lesslie Newbigin, “Christ and the World of Religions." Reformed Review 37, no. 3 (Spr 1984): 203. 
Dengan berkeyakinan dan menaruh seluruh komitmen kepada Kristus, tentu tidak bisa menerima klaim bahwa seluruh agama adalah jalan yang sama, yakni jalan yang menuju pada Allah yang sama. Pernyataan itu mengandung kontradiksi yang sangat besar, sebab penyataan Allah melalui Kristus, baik melalui kedatangan, inkarnasi, pelayanan, kematian, dan kebangkitan Kristus, menghadirkan alternatif bagi kegelapan dan kematian. Dan alternatif bagi kegelapan dan kematian adalah terang dan kehidupan. Alternatif tersebut hadir di hadapan dunia dan manusia melalui Pribadi Yesus Kristus. ${ }^{22}$

Newbigin juga mengungkapkan bahwa setiap umat manusia diberikan kemampuan untuk membangun dan menjalani kehidupan. Namun ironisnya, hal itu terpisah dari Allah, meski Allah yang telah mengaruniakannya. Dan fakta ini diungkapkan secara nyata melalui salib Kristus, yang terlihat melalui pelayanan Yesus Kristus, di mana keberadaan-Nya ditolak hingga berujung pada tindakan manusia menyalibkan Yesus Kristus. ${ }^{23}$ Keberadaan Yesus Kristus mengancam semua hal yang dianggap paling suci menurut manusia. Pernyataan ini menegaskan kembali pemikiran Newbigin, yakni agama bukanlah sarana di mana Allah menyatakan DiriNya maupun penebusan-Nya. Agama justru adalah area kegelapan.

Selain agama adalah area kegelapan, Newbigin mengungkapkan aspek yang lain mengenai "agama". Sejalan dengan pemikiran Hendrik Kraemer, seorang Kristen dalam menghadapi pribadi beragama lain haruslah bersifat dialektikal, yakni dengan menggabungkan "ya" dan "tidak". Artinya ketika seorang misionaris menghadapi pertanyaan "apakah ada wahyu lain, selain Yesus Kristus?", maka jawabannya dapat dinyatakan sebagai berikut:

Yes-for God reveals himself in nature, in history and in conscience; Nobecause it is only in the light of God's action in Christ that we can discern his revelation in nature, history and conscience. Apart from this, nature is an enigma full of both cruelty and beauty; history is a tangle of good and evil in which God's revelation of himself is by no means obvious; and conscience, like every other human faculty, is distorted by $\sin .{ }^{24}$

Berdasarkan pernyataan di atas, bila jawabannya "tidak", berarti merefleksikan penghakiman Allah atas dosa manusia, bahkan termasuk agama umat manusia di dalamnya. Dan bila jawabannya "ya", berarti merefleksikan pemeliharaan dan kemurahan Allah yang tidak meninggalkan dunia meski ciptaan-Nya memberontak terhadap Allah. Bahkan Allah sendiri

22 Ibid., 202.

3 Newbigin, The Open Secret, 176.

24 Newbigin, "Christ and the World of Religions", 203. 
berinisiatif untuk melakukan rekonsiliasi. ${ }^{25}$ Uraian ini mengindikasikan bahwa keberadaan agama dapat dilihat sebagai bagian dari kemurahan Allah, di mana melalui agama Allah masih berurusan dengan manusia. ${ }^{26}$ Namun, hal ini tidak dijelaskan lebih lanjut oleh Newbigin.

Berdasarkan penjelasan di atas, seluruh kehidupan yang ada di alam semesta ini secara natural adalah suatu proses menuju kematian, sedangkan yang ada di dalam Kristus adalah kehidupan. Kehidupan di dalam Kristus tidak berakhir kepada kematian, sebab Pribadi Kristus adalah Sang Kebangkitan dan Hidup. ${ }^{27}$ Oleh karena itu menurut Newbigin, seorang misionaris maupun seorang Kristen, perlu memikirkan bagaimana menghubungkan dan mengabarkan klaim Kristus kepada dunia. Bagian selanjutnya, penulis akan memaparkan cara pendekatan menurut pemikiran Newbigin.

\section{Pendekatan dan Sikap dalam Interaksi dengan Agama lain Menurut Lesslie Newbigin}

Selaras dengan pendahuluan Injil Yohanes, Newbigin menyatakan bahwa Yesus adalah Firman, dan melalui-Nya segala sesuatu dijadikan dan dicipta, serta Yesus adalah sumber hidup dan sumber terang yang memberikan terang kepada umat manusia. Pernyataan di mana kehadiran Yesus Kristus menghadirkan alternatif terang dan kehidupan sangatlah penting. Memikirkan uraian tersebut harusnya menimbulkan suatu dorongan yang bersifat mendesak untuk memberitakan Injil. ${ }^{28} \mathrm{Hal}$ yang sangat keliru bagi seorang Kristen, yang menyatakan dirinya telah berkomitmen sepenuhnya kepada Yesus Kristus, namun menaruh sedikit perhatian untuk menyatakan Kristus di tengah-tengah dunia. ${ }^{29}$

Dalam memandang agama lain, Newbigin sangat menekankan relasi yang setara antar pribadi manusia. Setiap manusia diciptakan oleh Allah menurut gambar dan rupa Allah, sehingga setiap manusia memiliki keterkaitan dengan Pribadi Kristus. ${ }^{30}$ Oleh karena itu, Newbigin menjelaskan bahwa seorang Kristen maupun misionaris perlu memegang prinsip ini ketika bertemu dan berdiskusi dengan seorang pribadi agama lain:

I meet the person simply as a witness, as one who has been laid hold of by Another and placed in a position where I can only point to Jesus as the one who can make sense of the whole human situation that my partner and I share as fellow

25 Ibid.

26 Newbigin, "Christ and the World of Religions", 207.

27 Lesslie Newbigin, "Christ and the World of Religions." Churchman 97, no. 1 (1983): 16.

28 Newbigin, "Christ and the World of Religions", 207.

29 Newbigin, The Open Secret, 174.

30 Ibid. 
human beings. This is the basis of our meeting. ${ }^{31}$

Prinsip yang demikian, mengakibatkan tiga implikasi dalam melakukan pendekatan untuk memberitakan Injil. Implikasi pertama, selain adanya tuntutan keharusan maupun desakan untuk bersaksi dan berdialog, Newbigin menolak pemberitaan Injil dengan nuansa "membujuk" ataupun "meyakinkan". ${ }^{32}$ Tujuan berdialog dalam pemberitaan Injil terhadap pribadi beragama lain adalah hanya sekadar menjadi saksi yang taat kepada Kristus. Menjadi saksi yang taat kepada Kristus, berarti dalam pemberitaan Injil tidak ada unsur "membujuk" maupun "meyakinkan" pribadi beragama lain. Pemberitaan Injil dengan nuansa seperti itu, mengindikasikan adanya spirit perekrutan.

Selain itu, menjadi saksi yang taat berarti di saat yang sama, seorang Kristen juga menerima penghakiman. Di hadapan salib, seorang Kristen akan disingkapkan dua hal: pertama, apakah ketaatannya telah sepenuhnya bersandarkan kepada Kristus?; dan yang kedua, apakah Injil yang diberitakannya telah berpadanan dengan Injil yang tercantum dalam Alkitab?33 Dengan kata lain, pertemuan terhadap pribadi beragama lain, sebenarnya mengandung risiko, yaitu mengoreksi dan menghakimi seorang Kristen. Pertemuan tersebut mengandung nuansa kritik bagi diri sendiri, di dalam menjalani kehidupan Kekristenan.

Implikasi yang kedua adalah sikap berdialog terhadap pribadi maupun masyarakat agama lain. Sebagaimana yang sudah dijelaskan bahwa manusia adalah makhluk yang diciptakan menurut gambar dan rupa Allah, maka seorang Kristen haruslah menyiapkan diri untuk mendengar. ${ }^{34}$ Seorang Kristen tidak bisa bersikap bahwa dirinya harus didengar oleh pribadi agama lain. Menuntut pribadi agama lain untuk mendengar, namun orang Kristen tidak bersedia untuk mendengar pribadi beragama lain, menunjukkan adanya ketidaksetaraan. Newbigin menambahkan bahwa adanya keinginan untuk mendengar dari sisi orang Kristen, menunjukkan adanya keinginan untuk belajar, yakni mendapatkan afirmasi bahwa segala sesuatu yang Bapa miliki adalah milik Kristus dan Ketuhanan Kristus mencakup seluruh alam semesta. Artinya, ketika berdialog dengan pribadi beragama lain, seorang Kristen semakin mengetahui bahwa segala sesuatu yang dinikmati oleh pribadi beragama lain bersumber dari Kristus.

Implikasi yang ketiga adalah ketika orang Kristen berdialog dengan pribadi agama lain, orang Kristen harus memercayakan dan berharap

31 Ibid. Bagian yang bercetak miring adalah penekanan penulis.

2 Ibid., 182.

3 Ibid.

34 Ibid., 183. 
kepada Roh Kudus, yakni berharap pada karya-Nya yang berdaulat untuk memakai dialog tersebut. Dengan adanya dialog tersebut, diharapkan pribadi beragama lain menjadi percaya kepada Kristus. ${ }^{35}$ Bila seorang Kristen saat berdialog dengan pribadi agama lain, mengesampingkan keyakinan yang demikian, berarti di saat yang sama seorang Kristen sedang menganggap remeh dialog tersebut. Hal ini berarti seorang Kristen tidak membuka kemungkinan bahwa momen tersebut dapat digunakan oleh Roh Kudus untuk menobatkan pribadi agama lain dan berkomitmen kepada Kristus. ${ }^{36}$

Dari pemaparan di atas terlihat bahwa pemikiran Newbigin sangat jelas menekankan perbedaan antara agama Kristen dan non-Kristen. Agama non-Kristen tentu tidak bisa dianggap sebagai jalan di mana Allah juga menganugerahkan keselamatan. Namun, distingsi yang bernuansa hitam putih tersebut, tidak diikuti dengan pandangan yang meremehkan kemanusiaan dari orang beragama lain. Lalu bagaimana dengan Bavinck? Bagian selanjutnya penulis akan memaparkan pemikiran Bavinck.

\section{Teologi Agama-Agama dalam Pemikiran Johan Herman Bavinck Agama Menurut Johan Herman Bavinck}

Dalam menjelaskan fenomena agama, Bavinck mengaitkannya dengan wahyu umum. Bavinck menjelaskan kaitan antara agama dan wahyu umum sebagai berikut:

General revelation is a very important factor in world history... It is divine concern for the totality of humankind and for each individual. His everlasting powers are plain to us; they overwhelm us; they strike us suddenly, in moments when we thought they were far away they creep up on us; they do not let go of us, even though we do our best to escape. Escaping, repressing is the human answer to God's revelation, an answer that becomes visible in the history of human religion. ${ }^{37}$

Pernyataan di atas memberikan penjelasan bahwa dengan memahami wahyu umum, orang Kristen dapat memahami fenomena agama, sebab wahyu umum menegaskan bahwa Allah tidak pernah meninggalkan umat manusia dan juga ciptaan-Nya - meski manusia telah jatuh ke dalam dosa. Dengan kata lain, Allah senantiasa berurusan dengan mengungkapkan Diri-Nya kepada setiap umat manusia di muka bumi ini.

Bertumpu pada pemikiran John Calvin, Bavinck setuju bahwa segala sesuatu yang menyangkut agama-agama, sangat berkait erat dengan

35 Ibid., 186.

36 Newbigin, The Open Secret, 187.

37 J.H. Bavinck, "Human Religion in God's Eyes: A Study of Romans 1:18-32." Scottish Bulletin of Evangelical Theology 12, no. 1 (Spr 1994): 50. 
gagasan benih agama (seed of religion). Benih agama yang ditanam dalam hati manusia, memengaruhi perjuangan maupun pencarian manusia terhadap hal-hal yang bersifat religius. Bavinck berpendapat bahwa tidak ada satu wilayah bahkan negara di dunia ini, yang hidup dengan tidak beragama. ${ }^{38}$ Dan melalui benih agama, Allah masih memberikan belas kasihan-Nya kepada umat manusia.

Untuk mempelajari dan melihat fenomena agama, Bavinck menyelidiki ke dalam kitab Roma 1:18-32. Dalam penyelidikannya, Bavinck menyatakan

The heathen who believes in gods and spirits and bows down before his idol, shows that he is touched by God and that God has in some sense sought him. But at the same time he reveals that he has himself been busy repressing what is absolutely necessary if one wants to come to God. ${ }^{39}$

Penjelasan Bavinck di atas, menegaskan bahwa Allah masih dan senantiasa berbicara kepada setiap pribadi dan setiap komunitas manusia. ${ }^{40}$ Artinya setiap umat manusia yang ada di muka bumi, selalu berhadapan dengan Allah yang sejati dan benar. Namun, konsekuensi dari tindakan manusia yang menekan, menindas, dan mengganti kebenaran, dapat dilihat dengan jelas dari perilaku manusia menyembah allah, yang adalah hasil imajinasinya.

Menurut Bavinck, terdapat empat kecenderungan yang hidup dalam hati manusia, yang ditemui dalam sejarah agama-agama, serta menjadi lawan yang kuat saat pemberitaan Injil dilakukan. Empat kecenderungan ini berkaitan erat dengan manusia yang menindas kebenaran dalam hati. Kecenderungan pertama adalah "that man tries to put God an immense distance away". ${ }^{41}$ Kecenderungan pertama ini dapat dihubungkan dengan memahami Allah yang dianggap jauh dan tidak memiliki kontak nyata dengan kehidupan manusia. Akibatnya, keberadaan Allah menjadi "memudar" dan menimbulkan celah kosong dalam hati manusia yang perlu diisi. Celah kosong yang harus diisi tersebut, mengakibatkan seseorang "haus" akan Allah. Untuk mengatasinya, seseorang berusaha untuk mengambil wujud suatu benda atau hal lainnya untuk dijadikan objek penyembahan. Fenomena ini sering kali dijumpai pada kepercayaan tradisional atau primitif, yang sering disebut animisme. Namun, dalam zaman modern pun, kecenderungan ini dapat ditemukan. Pada zaman seperti saat ini, di mana terdapat perkembangan teknologi yang sangat pesat, berbagai hal di dunia

8 Bavinck, The Impact of Christianity on The Non-Christian World, 91.

39 Bavinck, "Human Religion in God's Eyes: A Study of Romans 1:18-32", 49-50.

Ibid., 45.

41 J.H. Bavinck, "The Problem of Adaptation and Communication." International Review of Mission 45, no. 179 (July 1956): 309. 
modern seperti organisasi, uang, atau hal-hal lain dapat menggantikan posisi objek penyembahan yang ada dalam agama primitif. ${ }^{42}$ Dengan kata lain, meski zaman sudah modern dan semakin canggih, kecenderungan pertama ini tetap dapat ditemukan dalam kehidupan manusia, dengan berbagai variasi sekuler.

Kecenderungan kedua yang tampak di dalam hati manusia adalah "that God gradually disappears behind the moral order" ${ }^{43}$ Kecenderungan ini dapat dipahami dengan mengaitkan agama sebagai tuntutan dan kewajiban moral, agar hati manusia itu tidak menuding dengan perasaan bersalah. Di bagian ini, Bavinck pun memberikan peringatan kepada orang percaya atau orang Kristen bahwa seseorang yang mengklaim dirinya telah percaya kepada Kristus, juga memiliki kemungkinan untuk jatuh kepada kecenderungan yang kedua. Hal ini dapat dilihat dari kehidupan Kekristenan legalisme dan moralisme, yang sering kali mengaburkan cahaya Injil kasih karunia Allah. ${ }^{44}$

Kecenderungan yang ketiga yang ditemui di dalam sejarah agama adalah allah yang menyatu dengan alam semesta. ${ }^{45}$ Kecenderungan seperti ini, dapat ditemukan dalam sistem agama panteisme atau politeisme, dan dalam berbagai agama primitif. Dalam kecenderungan ini, konsepsi tentang Tuhan melibatkan pandangan mengenai posisi manusia, yakni

On the one side, man is regarded as nothing but an atom in the immensity of this universe; at the same time, however, since he forms such a part of the universe in which all the powers and faculties of the cosmos are focused, it is obvious that he himself is a kind of god. ${ }^{46}$

Kecenderungan keempat adalah "that God is felt to be the ocean of the ineffable and unapproachable mystery which is hidden behind the curtain of this illusory phenomenal world" ${ }^{47}$ Menurut Bavinck, kecenderungan keempat ini tidak mungkin membicarakan sesuatu yang relevan dan bernuansa positif tentang Yang Ilahi, sebab keberadaan Allah dianggap sebagai sesuatu yang tidak mungkin didekati sama sekali dan tidak ada kaitannya dengan kehidupan manusia. Segala sesuatu yang dibicarakan tentang Yang Ilahi hanyalah sesuatu yang negatif, dan ini dapat ditemukan dalam sistem mistis, seperti dalam filsafat Vedanta. ${ }^{48}$

42 Ibid., 309

43 Ibid.

44 Ibid.

45 Ibid.

46 Ibid., 310.

47 Ibid.

48 Ibid. Vedanta adalah satu dari enam sistem teologi Hindu dan merupakan inti dari filosofi Hindu. Vedanta mengajarkan bahwa semua agama mengarah ke tujuan yang sama dan menyatakan bahwa tujuan 
Melalui empat kecenderungan yang dijelaskan oleh Bavinck, maka terlihat jelas bahwa manusia senantiasa melakukan sesuatu terhadap Tuhan, dan manusia melakukannya secara berulang-ulang. ${ }^{49}$ Dari hal tersebut, Bavinck melihat adanya kaitan antara konsep manusia mengenai dirinya sendiri dengan aktivitas manusia, yang dinyatakannya sebagai berikut:

..that this assiduous, although most of the time unconscious, human activity has a considerable bearing upon man's conception of what he himself is and should be. When I ask, 'What are you doing with God?' I can go on to ask, 'What are you doing with yourself?' In our wrestling with God the meaning of our own being is at the same time always at stake. What is God and what am I? These two questions can never be separated from one another. The answer that I give to the first question implies an answer to the second question. Anthropology is always rooted in theological suppositions. ${ }^{50}$

Pernyataan yang diungkapkan Bavinck tersebut, menyiratkan adanya korelasi antara gagasan mengenai manusia dengan Tuhan.

Tindakan manusia yang diwujudkan dalam aktivitas sehari-hari, sebenarnya mengandung ekspresi dari tindakan manusia yang ditujukan kepada Tuhan. Dengan kata lain, tindakan manusia dalam bentuk praktik beragama, berkaitan erat dengan ide mengenai diri manusia. Oleh sebab itu, bagi Bavinck, agama secara teologis dapat dinyatakan "the way in which man experiences the deepest existential relations and gives expressions to this experience". ${ }^{51}$ Uraian dari pemikiran Bavinck tersebut, mengingatkan pada pemikiran Calvin di dalam Institutes yang menyatakan:

Without knowledge of self there is no knowledge of God: in the first place, no one can look upon himself without immediately turning his thoughts to the contemplation of God, in whom he "lives and moves" [Acts 17:28]. ${ }^{52}$

Berdasarkan pemaparan di atas, baik Calvin maupun Bavinck, keduanya memaparkan bahwa sesuatu yang berhubungan dengan diri manusia, juga berkaitan erat dengan Pribadi Allah. Jika pemahaman manusia mengenai Allah juga berkaitan erat dengan pemahaman manusia mengenai dirinya, maka korelasi di antara kedua hal ini juga berpengaruh pada relasi dengan pribadi agama lain. Bagian selanjutnya, penulis akan menjelaskan sikap dan

\footnotetext{
hidup adalah memiliki kesadaran seperti sang ilahi. Kesadaran seperti ini datang melibatkan usaha diri sendiri, tetapi di lain pihak mengajarkan bahwa hal ini diperoleh dari iluminasi langsung. Bagi Bavinck, pemahaman seperti ini tidak akan mungkin diperoleh sesuatu yang relevan dan positif. Mengenai Vedanta dapat dilihat dalam George A. Mather and Larry A. Nichols, Dictionary of Cults, Sects, Religions, and the Occult (Grand Rapids, Mich.: Zondervan Pub. House, 1993), 299-301.

49 Bavinck, "The Problem of Adaptation and Communication", 310.

50 Ibid. Bagian yang bercetak miring adalah penekanan penulis.

51 J.H. Bavinck, The Church between Temple and Mosque: A Study of the Relationship Between the Christian Faith and Other Religions (Grand Rapids, MI: Eerdmans, 1981), 112.

52 Calvin, Institutes, I.i.1.
} 
pendekatan orang Kristen terhadap agama lain.

\section{Sikap dan Pendekatan terhadap Agama lain Menurut Johan Herman Bavinck}

Berbicara mengenai pendekatan dengan orang-orang non-Kristen, Bavinck sangat memerhatikan sisi orang Kristen dan sisi penerima Injil. Bagi Bavinck, manusia dan kehidupannya bersumber dari Allah Tritunggal, sehingga tidak ada perbedaan derajat antara orang Kristen dan non-Kristen. Berdasarkan pemahaman ini, Bavinck menyatakan ada beberapa faktor yang perlu diperhatikan sebelum pemberita Injil melakukan interaksi dengan penerima Injil. Faktor yang pertama adalah si penerima Injil. Gaya berbicara orang dewasa terhadap seorang anak, akan berbeda bila berbicara dengan sesama orang dewasa. Profil lawan bicara akan memengaruhi cara seseorang berkomunikasi atau menyampaikan pesan. ${ }^{53}$ Bavinck mengungkapkan bahwa faktor pertama ini harus menjadi dasar pertimbangan ketika mengabarkan Injil. Berita Injil bukanlah berita abstrak, sebab Injil mengambil bentuk yang konkret dan terjadi perjumpaan yang nyata. Oleh sebab itu, seorang pemberita Injil perlu memahami profil dari pendengar Injil dan menyesuaikan dengannya, agar dapat mengomunikasikan Injil secara efektif.

Faktor kedua yang perlu dipikirkan adalah pribadi si pembawa Injil. ${ }^{54}$ Seorang pemberita Injil perlu memikirkan signifikansi dirinya, sebab dirinya adalah pembawa pesan Injil. Demi menjangkau orang hidup lainnya, maka Injil harus diberitakan melalui orang yang hidup pula. ${ }^{55}$ Dengan memerhatikan hal ini, maka terdapat relasi yang hidup antara pemberita Injil dengan si penerima Injil.

Faktor ketiga yang perlu dipikirkan adalah elemen waktu pertemuan. ${ }^{56}$ Memerhatikan momen yang tepat dalam pemberitaan Injil sangatlah penting bagi Bavinck. Berbagai kisah pemberitaan Injil yang memerhatikan momen yang tepat - dapat disebut dengan istilah Kairos - sangat jelas digambarkan dalam pelayanan Kristus dan juga para rasul di dalam Alkitab. Peristiwa saat Kristus bertemu dan menyampaikan Injil kepada perempuan Samaria di tepi sumur, akan berbeda ketika Kristus berbicara Injil terhadap Nikodemus. Setiap peristiwa memiliki kesulitan maupun peluang tersendiri. Oleh karena itu, pembawa Injil harus selalu memerhatikan dengan seksama peristiwa maupun momen ketika Injil diberitakan. Setiap momen yang terjadi adalah

82.

J.H. Bavinck, An Introduction to the Science of Missions (Phillipsburg, N.J: P \& R Publishing, 1960),

\footnotetext{
Ibid., 83.

Ibid., 83-84.

Ibid., 85.
} 
anugerah Allah.

Faktor terakhir yang perlu dipikirkan adalah tempat di mana pemberitaan Injil berlangsung. ${ }^{57}$ Ada perbedaan ketika pembawa Injil bertemu dengan penerima Injil di lingkungannya atau di rumahnya, dengan di rumah sakit ketika orang itu dalam keadaan kesepian. Setiap tempat memiliki suasana, kesulitan, dan peluang tersendiri. Menurut Bavinck, jika ingin membawa perubahan yang kekal dalam kehidupan seseorang, sebaiknya pertemuan dilakukan di kediaman penerima Injil berada, bukan di kediaman si pembawa Injil. ${ }^{58} \mathrm{Hal}$ ini juga dinyatakan dalam Alkitab, misalnya Kristus diceritakan datang ke rumah Zakheus atau Kristus bertemu dengan perempuan Samaria.

Empat faktor yang diuraikan di atas, akan memengaruhi pendekatan yang diambil. Bavinck menyatakan dua pendekatan, yaitu pendekatan dalam cakupan yang lebih luas (the approach in a broader sense) dan pendekatan saat pemberitaan Injil (the approach in preaching). ${ }^{59}$ Pendekatan dalam cakupan yang lebih luas dikaitkan dengan pendekatan komprehensif, yang tidak hanya dikaitkan dengan cara mengantarkan Injil, tetapi juga memerhatikan aspek-aspek lainnya, seperti sosial, pendidikan, dan aspek lain yang ditemukan di ladang misi. ${ }^{60}$ Sedangkan pendekatan saat pemberitaan Injil, dikaitkan dengan pendekatan kerygmatik yang berfokus hanya pada pemberitaan Injil. Bagi Bavinck, pendekatan kerygmatik selalu disertai dengan pendekatan komprehensif. Meskipun demikian, Bavinck juga mengungkapkan bahwa pendekatan dalam pemberitaan Injil, tidak pernah bisa dibakukan dalam bentuk kata-kata. ${ }^{61}$ Orang Kristen dapat melakukan pemberitaan Injil dengan pendekatan yang berbeda dengan dua pendekatan di atas. Hal terpenting adalah pembawa Injil perlu memikirkan empat faktor yang telah diuraikan untuk menentukan cara yang tepat dalam membawa

$57 \quad$ Ibid., 86.

58 Bavinck tidak menjelaskan secara detail, alasan dari pemberitaan Injil yang dilakukan di tempat tinggal si pendengar atau penerima Injil jauh lebih efektif. Bavinck hanya menyebutkan bahwa "each place has its own atmosphere, its own specific possibilities, and difficulties". Dengan mempertimbangkan hal tersebut, Bavinck berpendapat bahwa "..if [a Christian or evangelist] would bring about an abiding change in the life of a person, it is wise to meet him where he is, in his own house, in his own circle, and not where we are". Lihat dalam Bavinck, An Introduction to the Science of Missions, 86-87.

59 Ibid., 87.

60 Ibid.

61 Bavinck berpendapat bahwa pendekatan terhadap non-Kristen tidak bisa dibakukan bagaimana cara berinteraksinya, sebab "the approach is thus never simply a search for a words, it is at every moment an approach to living people, an approach which discloses itself in our entire attitude toward life". Lihat dalam Bavinck, An Introduction to the Science of Missions, 93. Bavinck memberikan contoh dengan menyebutkan konteks Paulus dalam pemberitaan Injil dengan menggunakan ekspresi perkataan dalam budaya Helenistik: "Paul and the other apostles did not hesitate to use numerous, highly specific words and expressions from Hellenistic culture, such as logos and soteria, which were, of course, loaded with wrong connotations, in the preaching of the gospel." Diambil dari J.H. Bavinck "Het probleem der Anknüpfung” dalam John Bolt, James Bratt, and Paul J. Visser, The J.H. Bavinck Reader (Grand Rapids, MI: William B. Eerdmans Publishing, 2013), 82. 
berita Injil di waktu yang tepat.

Namun, Bavinck mengungkapkan satu pendekatan yang tidak berkaitan dengan pendekatan kerygmatik maupun pendekatan komprehensif. Pendekatan ini disebut elenctics, yang diturunkan dari kata kerja Yunani elenchein, yang berarti "membujuk" (to persuade) atau dapat pula dipahami sebagai "untuk meyakinkan". ${ }^{62}$ Bavinck menjelaskan elenctics secara lebih lanjut sebagai berikut:

When we speak of elenctics we do well to understand it in the sense that it has in John 16:8. The Holy Spirit will convince the world of sin. The Holy Spirit is actually the only conceivable subject of this verb, for the conviction of sin exceeds all human ability. Only the Holy Spirit can do this, even though he can and will use us as instruments in his hand. Taken in this sense, elenctics is the science which is concerned with the conviction of sin. In a special sense then it is the science which unmasks to heathendom all false religions as sin against God, and it calls heathendom to a knowledge of the only true God. ${ }^{63}$

Gagasan elenctics ini, sangat berkaitan erat dengan titik tolak dalam mengomunikasikan Injil, yakni adanya peristiwa perjumpaan antara Allah dengan manusia. Umumnya si pembawa Injil memulai titik kontak pemberitaan Injil berdasarkan persamaan yang dapat diterima dalam agama atau akal manusia. Tetapi bagi Bavinck, titik kontak pemberitaan Injil tidak harus dimulai dari persamaan yang umum, tetapi dimulai dengan membuka "lembaran yang baru", yang didasarkan pada belas kasih dan kemurahan Allah di dalam pekerjaan-Nya. ${ }^{64}$

Gagasan elenctics terdiri dari tiga aspek. Aspek yang pertama adalah pembawa Injil harus menyadari bahwa sebelum memulai kontak, Allah telah terlebih dahulu hadir dengan kebenaran-Nya. ${ }^{65}$ Memahami bahwa Allah telah terlebih dahulu hadir, berarti menegaskan pernyataan dalam Kejadian 1:1: "Pada mulanya Allah menciptakan langit dan bumi" (TB). Sejak permulaan penciptaan, Allah-lah yang berinisiatif mencipta dan tidak pernah meninggalkan ciptaan-Nya.

Aspek kedua dari gagasan elenctics adalah penyataan Diri Allah di dalam Kristus harus berada di pusat pendekatan elenctics. ${ }^{66}$ Pernyataan ini sehubungan dengan menyingkapkan ketidakbenaran dalam terang kebenaran, yaitu kebenaran di dalam Kristus. Berkenaan dengan ini, argumen elenctics memiliki sifat profetik atau suara kenabian, sebab terdapat penyingkapan perjuangan-perjuangan agama, yang ternyata adalah

62 John Bolt, James Bratt, and Paul J. Visser, The J.H. Bavinck Reader, 83.

63 Bavinck, An Introduction to the Science of Missions, 222.

64 Bavinck, The Impact of Christianity on The Non-Christian World, 110.

65 John Bolt, James Bratt, and Paul J. Visser, The J.H. Bavinck Reader, 86.

66 Ibid. 
perjuangan pemberontakan melawan Allah yang benar. Melalui penyingkapan ini, pemberita Injil dapat memberikan jawaban dari kegelisahan hati manusia, yang hanya dapat ditemukan ketika manusia tunduk dan taat kepada otoritas dari Allah Tritunggal.

Aspek ketiga adalah signifikansi dari Pribadi Roh Kudus. ${ }^{67}$ Pribadi Roh Kudus adalah subyek elenctics. Dalam pemberitaan Injil dengan pendekatan elenctics, berarti Roh Kudus bekerja dan membuka titik tolak pemberitaan Injil berdasarkan kasih karunia Allah. Pribadi Roh Kudus adalah Pribadi yang membebaskan belenggu manusia, sehingga manusia dapat meresponi segala keberdosaan di dalam dirinya. Dengan demikian, Roh Kudus menggunakan perkataan pemberita Injil agar penerima Injil menerima Firman dan dapat meresponinya.

\section{Analisis Komparatif}

Setelah memaparkan pemikiran Newbigin dan Bavinck dalam menganalisis persoalan menyangkut agama-agama, penulis akan memberikan analisis komparatif di antara konsep Newbigin dan Bavinck akan agama dan pendekatan terhadap agama lain.

\section{Komparasi antara Konsep Agama Newbigin dan Bavinck}

Dalam membicarakan mengenai konsep agama, ada beberapa poin yang akan penulis soroti di antara pemikiran Newbigin dan Bavinck. Pertama adalah konsep agama yang dihubungkan dengan wahyu umum. Bagian poin pertama ini, kedua tokoh menghubungkan konsep agamanya dengan wahyu umum. Pembicaraan mengenai konsep agama yang dihubungkan dengan wahyu umum, terkandung aspek penciptaan di dalamnya. Karya penciptaan adalah hasil dari pekerjaan opera ad extra dari Allah Tritunggal. ${ }^{68}$ Dalam kaitan ini, Newbigin secara eksplisit menyatakan bahwa Allah juga menyatakan Diri-Nya melalui ciptaan, sejarah, dan hati nurani manusia. ${ }^{69}$ Sedangkan Bavinck menyoroti dari benih agama yang ada di dalam hati manusia. Maka dari itu, kedua tokoh tersebut, masih melihat keberadaan agama sebagai perjumpaan (encounter $)^{70}$ Allah dengan manusia-meski

67 Ibid., 87.

68 Herman Bavinck, In the Beginning: Foundations of Creation Theology (Grand Rapids: Baker Books House, 1999), 23-25.

69 Newbigin, "Christ and the World of Religions", 203.

70 Dalam menggambarkan fenomena agama sebagai respon manusia terhadap Allah, Bavinck terkadang menggunakan istilah "Divine-human encounters". Lihat dalam Bavinck, "Human Religion in God's Eyes: A Study of Romans 1:18-32", 50-51. Sedangkan Newbigin, dalam menggambarkan seseorang berkomitmen kepada Kristus, juga menggunakan kata "encounter". Lihat dalam Lesslie Newbigin, "The Basis, Purpose and Manner of Inter-Faith Dialogue." Scottish Journal of Theology 30, no. 3 (1977): $265-69$. doi:10.1017/S0036930600025503. 
manusia berulang-ulang menindas kebenaran tersebut.

Poin kedua adalah pandangan kedua tokoh terhadap keberadaan agama. Penulis terlebih dahulu menegaskan bahwa di paragraf sebelumnya dan sub-bab konsep agama Newbigin dan Bavinck, telah dinyatakan bahwa kedua tokoh ini menghubungkan keberadaan agama dengan wahyu umum. Namun, jika menyoroti pemikiran Newbigin, kaitan agama dan wahyu umum tidak dijelaskan secara lebih lanjut seperti yang ditemukan pada pemikiran Bavinck. Oleh sebab itu, penulis mendapati bahwa keberadaan agama dalam pemikiran Newbigin cenderung lebih negatif jika dibandingkan dengan pemikiran Bavinck.

Kecenderungan ini dapat terlihat dari definisi agama yang dinyatakan oleh kedua tokoh tersebut. Newbigin, yang cenderung negatif memandang agama, mendefinisikan agama sehubungan dengan komitmen kepada otoritas akhir tertinggi. ${ }^{71}$ Di bagian lain, Newbigin menyebutnya dengan istilah "of ultimate faith-commitment". ${ }^{72}$ Dengan cara demikian, Newbigin membaca agama dari perspektif Kristologis, yakni agama hanya menghadirkan realita kegelapan. Pernyataan ini diperkuat dengan mengkaitkan tindakan manusia yang menyalibkan Yesus Kristus. ${ }^{73}$ Sedangkan Kristus, menghadirkan alternatif terang dan kehidupan. ${ }^{74}$ Dalam kaitan ini, Newbigin memberikan penekanan terhadap spirit urgensi untuk mengabarkan Injil. Dengan menyadari bahwa agama hanyalah realita yang gelap dan berujung pada kematian, maka orang Kristen sudah seharusnya dengan mendesak memberitakan kabar Injil kepada dunia.

Bila menilik definisi agama menurut Bavinck, di mana Bavinck cenderung positif dalam memandang agama, tidak mengaitkannya dengan komitmen kepada otoritas tertinggi. Pemahaman ini bukan berarti Bavinck tidak berkomitmen pada Kristus. Tetapi dalam pembicaraan tentang agama, Bavinck melihat agama sebagai relasi eksistensi terdalam manusia, yang diwujudkannya dalam tindakan sehari-hari. ${ }^{75}$ Akibatnya, dalam pemikiran Bavinck tidak terdapat pernyataan yang menganggap bahwa agama adalah sesuatu yang buruk. Bavinck melihat bahwa aktivitas sehari-hari manusia memiliki korelasi dengan ekspresi yang ditujukan pada Tuhan. Jika manusia menolak Kristus, maka pribadi tersebut sedang menindas kebenaran, seperti yang telah dinyatakan oleh Paulus dalam Roma 1:18, yakni manusia berulang-ulang menindas kebenaran.

71 Newbigin, The Open Secret, 160.

72 Newbigin, "Christ and the Cultures." Scottish Journal of Theology 31, no. 1 (1978): 17. doi:10.1017/ S0036930600013041.

73 Newbigin, The Open Secret, 176.

74 Newbigin, "Christ and the World of Religions", 202.

75 Bavinck, The Church between Temple and Mosque, 112. 
Menurut Hendrik Kraemer (seorang misionaris), persoalan mengenai agama-agama lain, dapat dijawab dengan menggunakan kerangka wahyu umum. ${ }^{76}$ Bagi Kraemer, agama adalah "all inclusive systems and theories of life, rooted in a religious basis, and therefore at the same time embrace a system of culture and civilization and a definite structure of society and state" ${ }^{77}$ Bila Injil hendak dinyatakan kepada pribadi beragama lain, maka bagi Kraemer, Injil harus dihubungkan dengan persoalan dan kehidupan pribadi ataupun masyarakat. Kraemer mengungkapkan bahwa persoalan-persoalan yang menyangkut agama-agama, bukan hanya sekadar kumpulan ide mengenai nasib abadi dari kehidupan manusia (the eternal destiny of man). ${ }^{78}$ Jika pemahaman tentang agama lain hanya berfokus pada persoalan nasib abadi manusia saja, yakni selamat atau tidak selamat, maka Injil tidak memiliki relevansi bagi masyarakat agama lain. Injil yang diberitakan tidak berkaitan dengan sistem dan tatanan masyarakat tersebut. Bila konsep agama Newbigin dibandingkan dengan Bavinck dengan perspektif Kraemer, maka ada kecenderungan dalam pemikiran Newbigin berfokus pada "the eternal destiny of man" - hanya seputar selamat atau tidak selamatnya manusia.

Poin ketiga adalah kesetaraan manusia. Pribadi yang percaya kepada Kristus maupun yang menolak untuk tidak percaya Kristus adalah manusia yang diciptakan menurut gambar dan rupa Allah. Penulis tidak menemukan di antara Newbigin dan Bavinck, yang menyatakan bahwa orang Kristen lebih manusia dibandingkan dengan orang non-Kristen atau orang non-Kristen lebih rendah kedudukannya dibandingkan orang Kristen. Mengenai kesetaraan manusia, Newbigin menjelaskannya dengan keterkaitan manusia terhadap Pribadi Kristus. ${ }^{79}$ Bila meninjau pemikiran Bavinck, kesetaraan manusia dapat dilihat dari relasi eksistensial manusia, yang diekspresikan dalam tindakan sehari-hari. Orang Kristen yang menganggap rendah orang non-Kristen, sebenarnya sedang menganggap rendah dirinya sendiri. Dengan alasan tersebut, Bavinck menyatakan bahwa kehidupan manusia mencakup tiga dimensi. ${ }^{80}$

Bagian selanjutnya, penulis akan membandingkan antara sikap dan pendekatan Newbigin dengan Bavinck dalam berinteraksi dengan orang non-Kristen. Secara spesifik, penulis akan menyoroti dari metode

6raemer, The Christian Message in a Non-Christian World, 103.

7 Ibid., 102.

78 Ibid.

7ewbigin, The Open Secret, 174.

30 Visser menjelaskan pemikiran Bavinck yang menyatakan bahwa manusia memiliki cakupan kehidupan tiga dimensi, yakni relasi manusia dengan Allah, relasi manusia dengan manusia, dan relasi manusia dengan alam semesta atau lingkungannya. Cakupan kehidupan tiga dimensi ini saling berkaitan satu sama lain. Lihat Visser, "Religion, Mission, and Kingdom: A Comparison of Herman and Johan Herman Bavinck", 121. 
komunikasi Injil.

\section{Komparasi antara Metode Komunikasi Injil Newbigin dan Bavinck}

Sejauh pemaparan penulis terhadap pemikiran kedua tokoh ini, tidak ada indikasi bahwa kedua tokoh ini tidak tertarik untuk melakukan dialog dengan orang non-Kristen. Kedua tokoh justru menaruh perhatian terhadap orang non-Kristen. Dalam bagian ini, penulis menyoroti perbedaan di antara Newbigin dan Bavinck dalam melakukan pendekatan dan metode komunikasi Injil. Namun, untuk menjelaskan perbedaan di antara keduanya, penulis akan menelaah dari sudut pandang misionaris pula, yakni Eugene Nida dan David Bosch.

Perihal komunikasi Injil, David Bosch menyatakan bahwa dalam mewartakan Injil, di dalamnya terdapat permintaan tanggapan dari pendengar. Secara eksplisit, dinyatakan Bosch sebagai berikut:

Evangelism does aim at a response. On the basis of the reality of the fullness of time and the irruption of God's reign, Jesus summons his listeners, "Repent, and believe the gospel". "The calling is to specific changes, to renounce evidences of the domination of $\sin$ in our lives and to accept responsibilities in terms of God's love for our neighbour" ${ }^{81}$

Berdasarkan pernyataan Bosch tersebut, seorang pemberita Injil harus meminta tanggapan dari pendengarnya. Seruan panggilan Injil adalah panggilan untuk perubahan khusus, yakni bukti meninggalkan dominasi dosa atas manusia. Oleh sebab itu, pemahaman tentang pentingnya Injil bagi hidup manusia, perlu ditindaklanjuti dalam komunikasi Injil. ${ }^{82}$

Selain Bosch, Nida mengungkapkan hal yang senada tentang komunikasi Injil. Perihal komunikasi Injil ini, dijelaskan oleh Nida sebagai berikut:

Communication is power. There is a strangely modem ring about the fact that the Bible uses language in the sense of power. On the divine level God speaks and it is done, and, even on the human plane, the king commands and his servants perform. But in the human encounter with God there is an even deeper mystery, for not only does God "speak" to man, but by means of words man intercedes for man with the Almighty. ${ }^{83}$

Pernyataan Nida tersebut, di dalamnya mengandung indikasi bahwa dalam pemberitaan Injil ada kuasa di dalamnya. Pemberitaan Injil bukan sekadar Tuhan "berbicara" kepada manusia, tetapi melalui perkataan manusia, si

81 David J. Bosch, Transforming Mission: Paradigm Shifts in Theology of Mission (Maryknoll, N.Y.: Orbis Books, 1991), 413.

82 Cornelis J. Haak, "The Missional Approach: Reconsidering Elenctics Part 1." Calvin Theological Journal 44, no. 1 (April 2009): 37-38.

83 Eugene Nida, Message and Mission: The Communication of the Christian Faith (New York: William Carey Library, 1972), 225. 
pembawa Injil menjadi perwakilan Allah Yang Mahakuasa dalam menyampaikan berita kerajaan Allah bagi si pendengar Injil.

Bila kembali menyoroti pemikiran Newbigin dan Bavinck, dan kemudian membandingkan di antara keduanya menggunakan perspektif Bosch dan Nida, maka penulis mendapati beberapa poin perbedaan di antara Newbigin dan Bavinck. Pertama adalah posisi yang tidak sejajar antara pengabar Injil dan penerima Injil. Keseriusan berita Injil ditanggapi dengan spirit urgensi oleh Newbigin. Tetapi, Newbigin menjelaskan bahwa baik si pembawa Injil maupun si penerima Injil, keduanya akan menerima penghakiman. Dengan kata lain, keduanya berada pada posisi yang sejajar. Si pembawa Injil akan dihakimi dalam dua hal, yakni pertama, apakah si pembawa Injil bersandar pada Kristus?; dan kedua, apakah Injil yang diberitakan telah berpadanan dengan Injil yang ada di dalam Alkitab? Sedangkan si penerima Injil akan dihakimi menurut respon dan tanggapannya setelah mendengar Injil. Bila meninjau pemikiran Bavinck, posisi antara pemberita dan penerima Injil sangatlah berbeda. Injil yang dituju kepada penerima Injil, menuntut pembawa Injil untuk bersandar penuh kepada Roh Kudus. Hal ini ditujukan untuk menyingkapkan tirai yang menudungi sikap pemberontakan terhadap Allah.

Poin kedua adalah cara mengomunikasikan Injil. Dalam bagian ini, Newbigin sangat menekankan dialog, tanpa nuansa "membujuk" ataupun "meyakinkan". ${ }^{84}$ Tujuan berdialog bagi Newbigin adalah hanya sekadar menjadi saksi yang taat kepada Kristus. Menjadi saksi yang taat kepada Kristus, berarti dalam pemberitaan Injil tidak ada unsur "membujuk" maupun "meyakinkan" pribadi non-Kristen. Bagi Newbigin, pemberitaan Injil dengan nuansa seperti itu, mengindikasikan adanya spirit perekrutan. Sedangkan dalam pemikiran Bavinck, karena berita Injil begitu penting, maka Bavinck mengembangkan pendekatan elenctics, yang menuntut tanggapan dari pendengar Injil. Jika menggunakan perspektif Bosch maupun Nida, metode komunikasi Injil Newbigin cenderung bersifat pasif.

\section{Kesimpulan}

Sejauh ini penulis telah menunjukkan bagaimana pandangan Newbigin dan Bavinck dalam memandang keberadaan agama dan melakukan pendekatan dengan maksud untuk pengabaran Injil. Kedua tokoh ini berhasil menunjukkan bahwa sebagai orang Kristen yang berpandangan ekslusivisme dan juga berasal dari tradisi teologi Reformed, punya ketertarikan untuk berdialog dengan pribadi non-Kristen dan tidak memiliki anggapan yang

84 Newbigin, The Open Secret, 182. 
merendahkan orang yang belum percaya Kristus. Selain itu, perbedaan analisis antara teologi agama-agama Newbigin dengan Bavinck, dapat dilihat sebagai kelimpahan. Newbigin yang cenderung memandang agama-agama sebagai sesuatu yang negatif, memberikan kontribusi dengan menyatakan desakan dalam pengabaran Injil dan waspada terhadap spirit perekrutan. Bavinck menyoroti hal yang berbeda, yakni Bavinck memandang persoalan agama-agama sebagai sesuatu yang positif, namun tidak memberikan desakan dalam pemberitaan Injil. Bila merujuk pada komunikasi Injil, pemikiran Bavinck memberikan tempat bagi "membujuk", "meyakinkan", ataupun "menghakimi" pendengar. Kendati masing-masing tokoh terdapat kelebihan dan dan kekurangan, penulis melihat bahwa perspektif di antara keduanya dapat saling melengkapi dalam melihat fenomena dan menanggapi keragaman keberadaan agama.

\section{Bibliografi}

Barnes, Michael. Interreligious Learning: Dialogue, Spirituality and the Christian Imagination. Cambridge: CUP, 2012.

Bavinck, Herman. In the Beginning: Foundations of Creation Theology. Grand Rapids: Baker Books House, 1999.

Bavinck, J.H. The Impact of Christianity on The Non-Christian World. Grand Rapids, Michigan: William B. Eerdmans Publishing Company, 1948. . "The Problem of Adaptation and Communication." International Review of Mission 45, no. 179 (July 1956): 307-13. . An Introduction to the Science of Missions. Phillipsburg, N.J: P \& R Publishing, 1960.

. The Church between Temple and Mosque. Grand Rapids, Michigan:

William B. Eerdmans Publishing Company, 1981.

. "Human Religion in God's Eyes: A Study of Romans 1:18-32."

Scottish Bulletin of Evangelical Theology 12, no. 1 (Spr 1994): 44-52.

Bolt, John. "Why a Bavinck Institute? Why at Calvin Seminary?" Calvin Theological Journal 52, no. 2 (November 2017): 251-63.

Bolt, John, James Bratt, and Paul J. Visser, ed. The J.H. Bavinck Reader. Grand Rapids, MI: William B. Eerdmans Publishing, 2013.

Bosch, David Jacobus. Transforming Mission: Paradigm Shifts in Theology of Mission. Maryknoll, N.Y.: Orbis Books, 1991.

Calvin, John. Institutes of the Christian Religion. Diedit oleh John T. McNeill. Diterjemahkan oleh Ford Lewis Battles. Philadelphia: Westminster Press, 1960.

Castro, Emilio. "A Christocentric Trinitarian Understanding of Mission." International Review of Mission 89, no. 355 (October 2000): 584-91. 
Dupuis, Jacques. Towards a Christian Theology of Religious Pluralism. Maryknoll: Orbis, 1997.

D'Costa, Gavin. Christianity and World Religions: Disputed Questions in the Theology of Religions. Oxford: Wiley-Blackwell, 2009.

Goheen, Michael W. "As the Father Has Sent Me, I Am Sending You": J. E. Lesslie Newbigin's Missionary Ecclesiology. PhD diss., Universiteit of Utrecht, 2000. Diakses 2 Februari 2021, https://dspace.library.uu.nl/bitstream/ handle/1874/597/inhoud.htm?sequence $=38$

Haak, C J. (Cornelis Jan). “The Missional Approach: Reconsidering Elenctics Part 1." Calvin Theological Journal 44, no. 1 (April 2009): 37-48.

Kraemer, Hendrik. The Christian Message in a Non-Christian World. London: Edinburgh House Press, 1938.

Mather, George and Larry A. Nichols. Dictionary of Cults, Sects, Religions, and the Occult. Grand Rapids, Mich.: Zondervan Pub. House, 1993.

Moore-Keish, Martha L. "Divine Freedom and Human Religions: A Reformed Theologian Approaches Comparative Theology." Theology Today 75, no. 3 (October 2018): 281-96. doi:10.1177/0040573618791732. Newbigin, Lesslie. "Basis, Purpose and Manner of Inter-Faith Dialogue." Scottish Journal of Theology 30, no. 3 (1977): 253-70. doi:10.1017/ S0036930600025503.

. "Christ and the Cultures." Scottish Journal of Theology 31, no. 1 (1978): 1-22. doi:10.1017/S0036930600013041.

. The Light Has Come: An Exposition of the Fourth Gospel. Grand Rapids, Mich.: W.B. Eerdmans, 1982.

. "Christ and the World of Religions." Churchman 97, no. 1 (1983): $16-30$.

. "Christ and the World of Religions." Reformed Review 37, no. 3 (Spr 1984): 202-13.

. "Religious Pluralism and the Uniqueness of Jesus Christ." International Bulletin of Missionary Research 13, no. 2 (April 1989): 50-54. . "Way out West: The Gospel in a Post-Enlightenment World." Touchstone (US) 5, no. 3 (Sum 1992): 22-24. . The Open Secret: An Introduction to the Theology of Mission, rev. ed. Grand Rapids, Mich.: W.B. Eerdmans, 1995.

Nida, Eugene. Message and Mission: The Communication of the Christian Faith. New York: William Carey Library, 1972.

Pope John Paul II. “Redemptoris Missio," Vatican.va, December 7, 1990. https://www.vatican.va/content/john-paul-ii/en/encyclicals/documents/hf_jp-ii_enc_07121990_redemptoris-missio.html

Pope Paul VI. "Declaration on the Relation of the Church to non-Christian 
Religions-Nostra Aetate." Vatican.va, October 28, 1965.

https://www.vatican.va/archive/hist_councils/ii_vatican_council/ documents/vat-ii_decl_19651028_nostra-aetate_en.html

Smith, Gary Scott, ed. The Oxford Handbook of Presbyterianism. New York: Oxford University Press, 2019.

Taylor, Kathleen. "Talking with Other Religions." The Way 59, no. 1 (January 2020): 47-57.

Visser, P J. (Paul Jan). "Religion, Mission, and Kingdom: A Comparison of Herman and Johan Herman Bavinck." Calvin Theological Journal 45, no. 1 (April 2010): 117-32. 